\title{
The impact of virtual infant simulators in tackling under-18 conception rates in Rotherham, UK
}

\section{Nicole Chavaudra}

There are extremes of opinion around the use of virtual infant simulators (VIS), and very few issues are likely to fuel such heated debates amongst teenage pregnancy professionals. Do VIS actually make a difference to teenage pregnancy rates, or indeed any other aspects of sexual behaviour amongst young people? The evidence is mixed.

VIS have been used in some areas of the UK for a number of years as part of a wider strategy to prevent teenage pregnancy and teach parenting skills. The dolls are replica babies programmed to behave as real babies, and require the same responses including attending to triggers such as crying, nappy changing and feeding. VIS are available in different ethnic models, can be programmed to different behaviour modes, and are available in male and female models, newborn or older, drug- and alcoholdependent and breastfed or bottle-fed models. In Rotherham in the UK, VIS have been used widely by different agencies and professionals including the youth service, schools and nurses. A computer chip in the simulator records the care received by the doll, the results of which can be discussed with the young person.

A number of reviews of VIS programmes have been conducted in the USA, with mixed results. There is evidence from some of these reviews that when well delivered and comprehensive, VIS programmes can result in a desire to delay parenthood by young people. ${ }^{1}$ Another review found that participation in such programmes frequently confirmed the view of parenthood held by the young person prior to involvement, and that where young people held a positive view of young parenthood, the negative aspects of the experience were overlooked. ${ }^{2}$ Also, a further review found that two identical programmes, one using VIS and one without, produced the same outcomes. ${ }^{3}$ There is, however, no evidence to support the hypothesis that using electronic simulator babies decreases under-18 conceptions or changes sexual behaviour.

The local Rotherham experience is largely consistent with the findings of the USA reviews. There is no doubt that using electronic simulators can support the teaching of parenting skills, and there is local anecdotal evidence that their use, when delivered as part of a comprehensive sex and relationships education programme, can result in a

J Fam Plann Reprod Health Care 2007; 33(1): 35

Rotherham Primary Care Trust, Rotherham, UK Nicole Chavaudra, BA, Teenage Pregnancy Strategy Co-ordinator

Correspondence to: Ms Nicole Chavaudra, Rotherham Primary Care Trust, Oak House, Moorhead Way, Bramley, Rotherham S66 1YY, UK. E-mail: Nicole.chavaudra@rotherhampct.nhs.uk stronger desire to delay parenthood. However, I personally have many concerns regarding the use of VIS as a tool for tackling teenage pregnancy. The confirmation of prior-held beliefs revealed by one of the USA reviews appears to be consistent with the Rotherham experience, with many young mothers in the borough having participated in the scheme in school. Where programmes are delivered without a comprehensive education programme detailing the wider consequences of pregnancy and parenthood in terms of finances, emotions, relationships and future achievements, the result can be an increased desire for the young person to become pregnant. For many young people at particular risk of becoming teenage parents the attention received whilst caring for the doll reinforces the desire for parenthood.

A major factor for those considering using the VIS dolls should be the costs involved. The estimated cost for a doll over its lifetime is $£ 1000$, including the initial cost of the product, maintenance and associated equipment such as clothing, bottles and changing bags, with additional costs incurred in paying staff to be on call whilst the simulators are in the care of the young people. It is questionable whether the delivery of the education programme alone, without the added novelty value of the VIS, would achieve the same desire to delay parenthood.

Whilst there is evidence that use of VIS can stimulate a desire to delay parenthood, programme leaders should also consider whether this desire would be similar in young people who have completed the education programme without the use of the VIS to those who have, and as such whether the cost implications are worth the outcomes in terms of teenage pregnancy rates. These resources may be better utilised in focusing on developing the aspirations of young people at risk of becoming young parents, and on delivery of comprehensive sex, relationships and parenting education programmes. The use of an expensive electronic simulator does not demonstrate the emotional elements associated with a human baby and pregnancy, and programme leaders should consider the outcomes they hope to achieve from the use of VIS before resources are allocated.

Statements on funding and competing interests Funding None identified.

Competing interests None identified.

References

1 Malinowski A, Stamler LL. Adolescent girls' personal experience with Baby Think It Over simulator. Am J Matern Child Nurs 2003; 28: 205-211.

2 Kralewski J, Stevens C. Does mothering a doll change teens' thoughts about pregnancy? Pediatrics 2000; 105: 30.

3 Barnett E. Evaluating "baby think it over" simulators: a comparison group study. Adolescence 2006; 41: 103-110.

\section{LETTERS TO THE EDITOR}

Letters to the Editor are welcome and generally should not exceed 600 words or cite more than five references. For comments on material published in the most recent issue of the Journal, correspondence should be received within 4 weeks of dispatch of that Journal to be in time for inclusion in the next issue. When submitting letters correspondents should include their job title, a maximum of two qualifications and their address(es). A statement on competing interests should also be submitted for all letters. Letters may be submitted to the Editor or the Journal Editorial Office (details on page 1). 